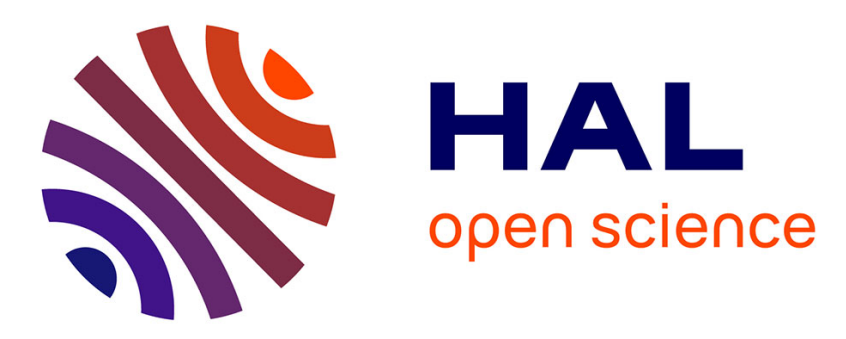

\title{
Differing effects of prosaccades and antisaccades on postural stability.
}

\author{
Agathe Legrand, Karine Doré Mazars, Julie Lazzareschi, Christelle Lemoine, \\ Isabelle Olivier, Julien Barra, Maria Pia Bucci
}

\section{- To cite this version:}

Agathe Legrand, Karine Doré Mazars, Julie Lazzareschi, Christelle Lemoine, Isabelle Olivier, et al.. Differing effects of prosaccades and antisaccades on postural stability.. Experimental Brain Research, 2013, 227 (3), pp.397-405. 10.1007/s00221-013-3519-z . hal-00850979

\section{HAL Id: hal-00850979 \\ https://hal.science/hal-00850979}

Submitted on 24 Feb 2021

HAL is a multi-disciplinary open access archive for the deposit and dissemination of scientific research documents, whether they are published or not. The documents may come from teaching and research institutions in France or abroad, or from public or private research centers.
L'archive ouverte pluridisciplinaire HAL, est destinée au dépôt et à la diffusion de documents scientifiques de niveau recherche, publiés ou non, émanant des établissements d'enseignement et de recherche français ou étrangers, des laboratoires publics ou privés. 


\section{Differing effects of prosaccades and antisaccades on postural stability Agathe Legrand · Karine Doré Mazars • \\ Julie Lazzareschi • Christelle Lemoine • \\ Isabelle Olivier · Julien Barra • Maria Pia Bucci}

\begin{abstract}
The goal of the study was to examine the effect of different types of eye movements on postural stability. Ten healthy young adults ( $25 \pm 3$ years) participated in the study. Postural control was measured by the TechnoConcept $(C$ platform and recorded in Standard Romberg and Tandem Romberg conditions while participants performed five oculomotor tasks: two fixation tasks (central fixation cross, without and with distractors), two prosaccade tasks toward peripheral targets displayed $4^{\circ}$ to the left or to the right of the fixation cross (reactive saccades induced by a gap $0 \mathrm{~ms}$ paradigm and voluntary saccades induced by an overlap $600 \mathrm{~ms}$ paradigm) and one antisaccade task (voluntary saccade made in the opposite direction of the visual target). The surface, the length, and the mean speed of the center of pressure were analyzed. We found that saccadic eye movements improved postural stability with respect
\end{abstract}

A. Legrand · K. D. Mazars · J. Lazzareschi · C. Lemoine · J. Barra $\cdot$ M. P. Bucci

Laboratoire de Psychologie et Neuropsychologie Cognitives, FRE 3292 CNRS, IUPDP, Université Paris Descartes,

Boulogne-Billancourt, France

K. D. Mazars

Institut Universitaire de France, Paris, France

I. Olivier

Laboratoire TIMC-IMAG, UMR CNRS 5525, Faculté de médecine, Université Joseph Fourier, Bâtiment Jean Roget, 38700 La Tronche, France

\section{Present Address:}

A. Legrand $(\varangle) \cdot$ K. D. Mazars $\cdot$ C. Lemoine

Laboratoire Vision Action Cognition EAU01, Sorbonne Paris

Cité, Institut de Psychologie, IUPDP, Université Paris Descartes,

71, avenue Edouard Vaillant, 92774 Boulogne-Billancourt,

France

e-mail: agathe.legrand@etu.parisdescartes.fr to the fixation tasks. Furthermore, antisaccades were found to decrease postural stability compared to prosaccades (reactive as well as voluntary saccades). This result is in line with the U-shaped nonlinear model described by Lacour et al. (Neurophysiol Clin 38:411-421, 2008), showing that a secondary task performed during a postural task could increase (prosaccade task) or decrease (antisacade task) postural stability depending on its complexity. We suggest that the different degree of attentional resources needed for performing prosaccade or antisaccade tasks are, most likely, responsible for the different effect on postural control.

Keywords Posture - Eye movements - Antisaccades · Prosaccades $\cdot$ Dual-task

\author{
Present Address: \\ M. P. Bucci \\ Laboratoire de Physiopathologie et neuroprotection des atteintes \\ du cerveau en développement UMR 676 INSERM, Hôpital \\ Robert Debré, Université Paris Diderot, 48 Bd Sérurier., \\ 75019 Paris, France \\ Present Address: \\ J. Barra \\ Laboratoire Mémoire Cognition EAU02, Institut de Psychologie, \\ IUPDP, Université Paris Descartes, Sorbonne Paris Cité, \\ Boulogne-Billancourt, France
}




\section{Introduction}

Postural control has long been considered as an automatic system, but recent studies have identified a process of postural regulation in cases of both simple and more complicated tasks, especially when the latter involve attentional processes (Blanchard et al. 2005; Palluel et al. 2010). The mobilization of such attentional resources depends on many factors, such as availability of sensory information (Shumway-Cook and Woollacott 2000), task complexity and age (Woollacott and Shumway-Cook 2002), or postural skills of the participants (Lajoie et al. 1993).

In 1985, Kerr et al. were the first to show, using the dualtask paradigm, that the postural control of young adults is attention dependent and that postural stability is not affected by all the cognitive tasks in the same way. In 1993, Lajoie et al. (1993) and more recently Barra et al. (2006) described the correlation between the complexity of postural conditions and the associated attentional costs.

In other words, visual inputs which have a central role in the control of posture are known to require attention, and attention is also involved in the execution of saccadic eye movements (Deubel and Schneider 1996; Belopolsky and Theeuwes 2009). Thus, saccades have an impact on balance but also on the adjustment of the vestibuloocular function (Leigh and Zee 2006). Several structures of the central nervous system in the cerebral cortex (frontal, parietal, occipital) and in the brainstem (paramediane pontine reticular formation and superior colliculus) play an important role in postural control as well as in the programming and execution of saccadic eye movements (Leigh and Zee 2006); consequently, one could expect interferences between oculomotor and postural control.

Indeed, the effect of saccadic eye movements on postural control has long been investigated. For instance, some authors (Uchida et al. 1979; Stoffregen et al. 2007; Rougier and Garin 2007) showed an improvement in postural stability while saccadic eye movements are performed. In contrast, other researchers (White et al. 1980; Straube et al. 1989; Glasauer et al. 2005) found that eye movements did not modify or decrease postural stability. Note, however, that the controversial results could be due to the varying experimental conditions used in the different studies, such as the type of postural test (bipodal or unipodal position) or characteristics of saccades (saccade amplitudes varying from $4^{\circ}$ to $40^{\circ}$, horizontally or vertically directed saccades).

In normal young participants, the surface of center of pressure $(\mathrm{CoP})$, length of $\mathrm{CoP}$, and mean speed of CoP are good spatio-temporal variables currently used to study the variation of postural control (Stoffregen et al. 2007; Rougier and Garin 2007). Other postural parameters can be used when a visual isolated event is manipulated. For example, the time to onset of a modification of amplitude of CoP after neck muscle or galvanic stimulation in the opposite direction of gaze is observed (Bove et al. 2009; Grasso et al. 1999). Nevertheless, the examination of those parameters is not possible when a series of saccades is manipulated.

The goal of the present study was to examine the effect of saccadic eye movements on postural control in young adults. In order to gain a better insight into how saccades influence postural control, we examined posture while different types of saccades were performed: prosaccades (saccades made toward the target, in a reactive and voluntary mode) as well as antisaccades (saccades made in the opposite direction of the target) and two types of fixation: without and with distractors. Furthermore, two postural conditions were used to change postural stability, the Standard Romberg (ST), and the Tandem Romberg (TR) positions, and the latter being more challenging still than the former. Our driving hypothesis was that a high-level cognitive task such as that involved in antisaccades could decrease postural stability, in particular in the more complex posture (TR).

\section{Material}

\section{Platform posturography}

A platform (principle of strain gauge) consisting of two dynamometric clogs (Standards by Association Française de Posturologie, produced by TechnoConcept $\odot$, Céreste, France) was used to measure postural stability. Excursions of CoP were recorded for $25.6 \mathrm{~s}$. The platform posturography is equipped with an analog-digital converter (16 bit), and the acquisition frequency is $40 \mathrm{~Hz}$.

\section{Participants}

Ten young adults ( $25 \pm 3$ years) participated in the study. All participants had good corrected visual acuity ( $\geq 20 / 25)$, tested with the Monoyer scales, at a distance of $5 \mathrm{~m}$; they had normal binocular vision ( $<60 \mathrm{~s}$ of $\operatorname{arc})$ as established by the TNO random dot test (Netherlands Organisation of Applied Scientific Research Test of Stereoacuity).

The investigation adhered to the principles of the Declaration of Helsinki and was approved by our Institutional Human Experimentation Committee. We obtained the participants consent after we explained the experimental procedure. 


\section{Methods}

Visual tasks

Five visual tasks were designed and tested in separate sessions: two fixation tasks (without and with distractors) and three saccadic tasks (prosaccades: reactive and voluntary saccades and antisaccades). Stimuli were presented on the PC screen $(19$ inches, resolution: $800 \times 600$ pixels, luminance of background: $7 \mathrm{~cd} / \mathrm{m}^{2}$ ) adjusted at the eye level in front of the participant. It should be noted that eye movements are not recorded in this study. Most participants were accustomed to oculomotor experiments, and each participant was trained to the oculomotor tasks used here before postural recording.

Stimuli were white on gray background $\left(4.8 \mathrm{~cd} / \mathrm{m}^{2}\right)$. The fixation cross $\left(0.36^{\circ}\right)$ was displayed at the center of the screen. For all the visual tasks (except Fixation without distractor), a peripheral stimulus (saccade target or distractor) was a white disk $\left(1.5^{\circ}\right.$ diameter, $\left.38 \mathrm{~cd} / \mathrm{m}^{2}\right)$ with a small gray disk in the center $\left(0.2^{\circ}\right)$, randomly presented at $4^{\circ}$ leftward or rightward from the central fixation cross along the horizontal axis. The experimental paradigms are illustrated in the Fig. 1.

Fixation tasks

\section{Fixation without distractor}

Participants had to fixate the white cross that appeared at the center of the screen for $25.6 \mathrm{~s}$ (Fig. 1a).

\section{Fixation with distractors}

Participants had to fixate the cross for $25.6 \mathrm{~s}$ while a peripheral distractor randomly appeared leftward or rightward from the central cross (Fig. 1b).

Saccadic tasks

\section{Prosaccade tasks}

Horizontal, visually guided saccades were elicited by using two different temporal paradigms, namely simultaneous
Fig. 1 Examples of visual events displayed in the five visual tasks: fixation without distractor (a), fixation with distractors (b), reactive saccades elicited with the simultaneous paradigm (c), voluntary saccades elicited with the overlap paradigm (d), and antisaccades (e). The arrows represent the saccadic eye movements. See text for details

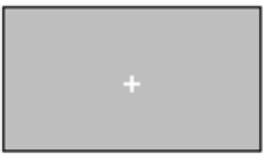

a fixation without distractor

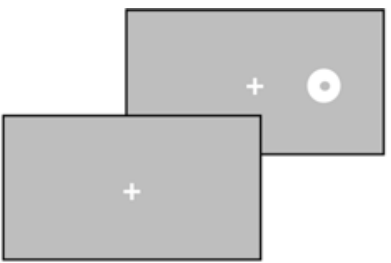

b fixation with distractors

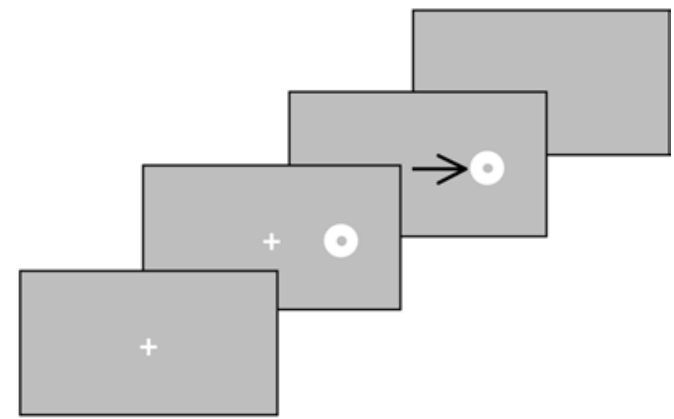

d voluntary saccades

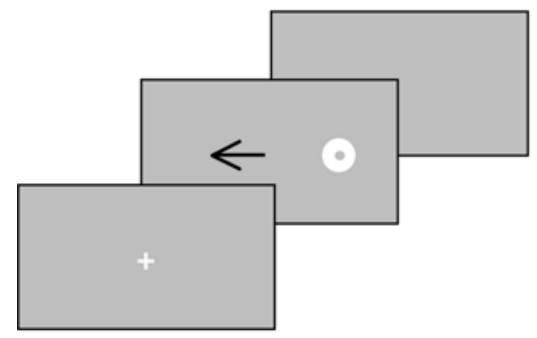

e antisaccades 
(gap $=0 \mathrm{~ms}$ ) and overlap paradigms. In the simultaneous paradigm, the target appears simultaneously with the offset of the central fixation point, while in the overlap paradigm, the central fixation point stays on and, at the same time, a target appeared to the right or to the left side. The simultaneous paradigm (gap $=0 \mathrm{~ms}$ ) is well known to induce reactive saccades, whereas the overlap paradigm stimulates voluntary saccades needing disengagement of attention in order to perform the saccade (Fischer 1987).

For more details, before each saccade target, a central fixation cross was switched on for a random period of 400 , 600 , or $800 \mathrm{~ms}$.

For reactive saccade, after a variable delay $(400,600$ or $800 \mathrm{~ms}$ ), the central fixation cross was switched off, and simultaneously, a peripheral target stayed on for $300 \mathrm{~ms}$. The screen was blank for the following $500 \mathrm{~ms}$ (Fig. 1c).

For voluntary saccades, the central fixation cross was illuminated for 400, 600, or $800 \mathrm{~ms}$. The saccade target appeared while the fixation cross stayed on, both were visible for $600 \mathrm{~ms}$, that is, the overlap period. Then, the central fixation cross was switched off, and the peripheral target remained for $300 \mathrm{~ms}$, followed by the blank screen of $500 \mathrm{~ms}$ (Fig. 1d).

In both prosaccade tasks (simultaneous and overlap paradigms), participants were instructed to make a saccade to the peripheral target (around 18 reactive and 12 voluntary saccades for the postural recording duration).

\section{Antisaccade task}

Antisaccades have also been stimulated (Fig. 1e). This task was originally introduced by Hallet (1978): It consisted in presenting a visual stimulus on one side and asking participants to make a saccade to the opposite side. The central cross was illuminated for a random period of 400, 600, or $800 \mathrm{~ms}$. Simultaneously to the cross extinction, a peripheral stimulus appeared and stayed on for $300 \mathrm{~ms}$. The screen was blank for the following $500 \mathrm{~ms}$. The sequence of visual events was similar to those used in the simultaneous (gap $=0 \mathrm{~ms}$ ) paradigm, but in this case, participants were invited to make an antisaccade to the opposite side of the stimulus as soon as possible.

Postural recording procedure

Participants stood on the platform, in front of the screen located $114 \mathrm{~cm}$ away from them. Postural measurements were performed in two different postural conditions: Standard Romberg and Tandem Romberg. In the Standard Romberg condition, the heels were placed $4 \mathrm{~cm}$ apart and feet positioned symmetrically with respect to the participant's sagittal axis at a $30^{\circ}$ angle. In the Tandem Romberg position, the feet were placed slightly apart $(4 \mathrm{~cm})$ in a semi-tandem position with the dominant foot in front of the non-dominant one.

The duration time of each postural recording was $25.6 \mathrm{~s}$. For each condition ( 5 visual tasks $\times 2$ postural positions), four trials were run. Thus, a total of 40 postural measures were recorded for each participant. The order of the visual tasks and of the postural conditions varied randomly across participants. Participants were asked to stay as stable as possible, with the arms along the body.

\section{Data processing}

To quantitate the effect of visual tasks and the postural performance from data obtained from the platform, we analyzed the surface area, the length, and the mean speed of the CoP. The surface area and the length allow to efficiently measure CoP spatial variability (Chiari et al. 2009). The surface of CoP corresponds to an ellipse with $90 \%$ of $\mathrm{CoP}$ excursions. The length of $\mathrm{CoP}$ is the path of the center of pressure. These two postural parameters are uncorrelated; indeed, the inner surface of the same length may be different (Gagey and Weber 1999; Vuillerme et al. 2008). The mean of speed represents a good index of the amount of neuromuscular activity required to regulate postural control (Maki et al. 1990; Geurts et al. 1993). Figure 2 shows stabilogramms of a representative participant in two different postural conditions recorded during the five visual tasks.

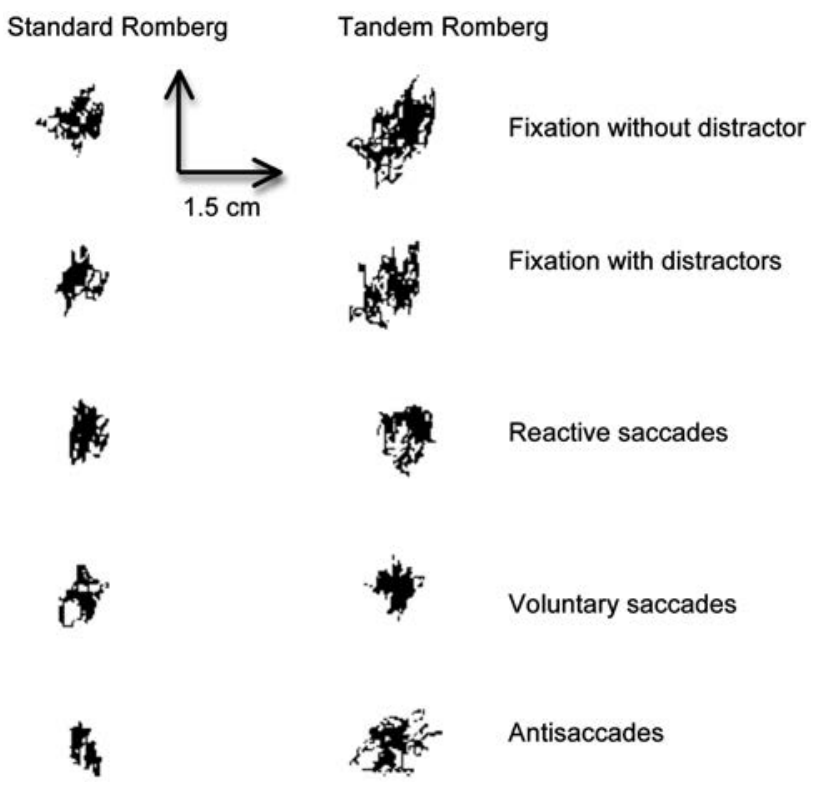

Fig. 2 Stabilogramms representing CoP displacements for one participant as a function of five visual tasks (fixation without and with distractors, reactive and voluntary prosaccades, and antisaccades) and difficulty of postural task (SR Standard Romberg and TR Tandem Romberg). The vertical and horizontal axes represent antero-posterior (AP) and medio-lateral (ML) CoP displacements, respectively 
Statistical analysis

Analyses of variance (using the ANOVA test) were performed to compare data in the different visual tasks with the different type of postural conditions: two-way ANOVA: 5 Visual tasks (fixation without and with distractors, reactive and voluntary prosaccades, and antisaccades) $\times 2$ postural conditions (Standard and Tandem Romberg). Post hoc comparisons were made with the Fischer's least significant differences (LSD) test used to explore further and compare the mean of one oculomotor task or postural positions with the mean of another. The effect of a factor was considered as significant when the $p$ value was below 0.05 .

\section{Results}

Analysis of the surface of CoP (Fig. 3) showed a significant effect of the postural condition $\left(F_{(1,9)}=40.10\right.$, $p<0.001)$ that was greater in Tandem than in Standard Romberg condition. There was also a significant effect of the visual task $\left(F_{(4,36)}=11.71, p<0.001\right)$. Interestingly, there was a significant interaction between the visual task and the postural condition $\left(F_{(4,36)}=2.66, p<0.05\right)$. The effect of the visual task did not reach significance in standard Romberg condition $\left(F_{(4,36)}=2.0, p=0.1\right)$, in contrast to the tandem Romberg condition $\left(F_{(4,36)}=7.70, p<0.01\right)$. While the antisaccade task did not differ from the prosaccade task (compared to reactive saccades, $p=0.5$ and to voluntary ones $p=0.2$ ), the surface of $\mathrm{CoP}$ was greater in both fixation tasks compared to that of saccadic tasks $\left(F_{(1,9)}=19.09, p<0.01\right)$.

Analysis of the length of CoP (Fig. 4) showed a significant effect of postural condition, with smaller values in the Standard than in the Tandem Romberg condition

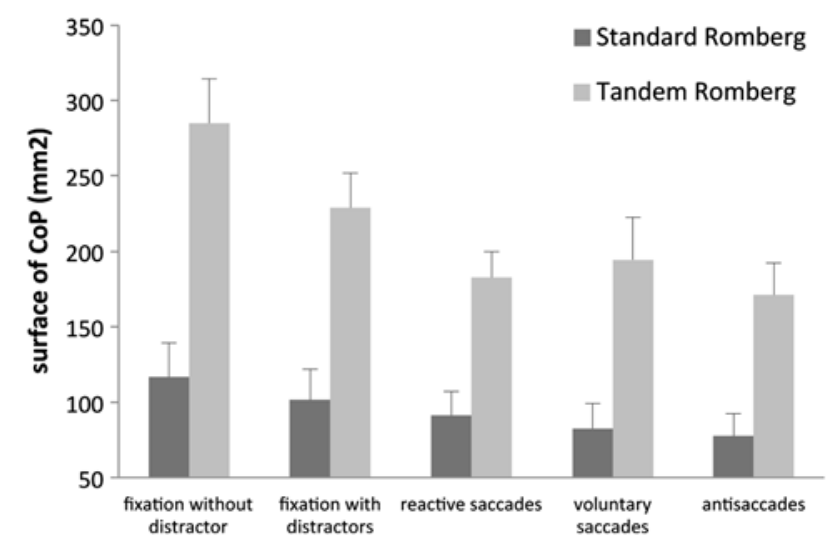

Fig. 3 Mean and standard deviation of surface of CoP in SR and TR conditions in the five visual tasks (fixation without and with distractors, reactive, and voluntary prosaccades and antisaccades)

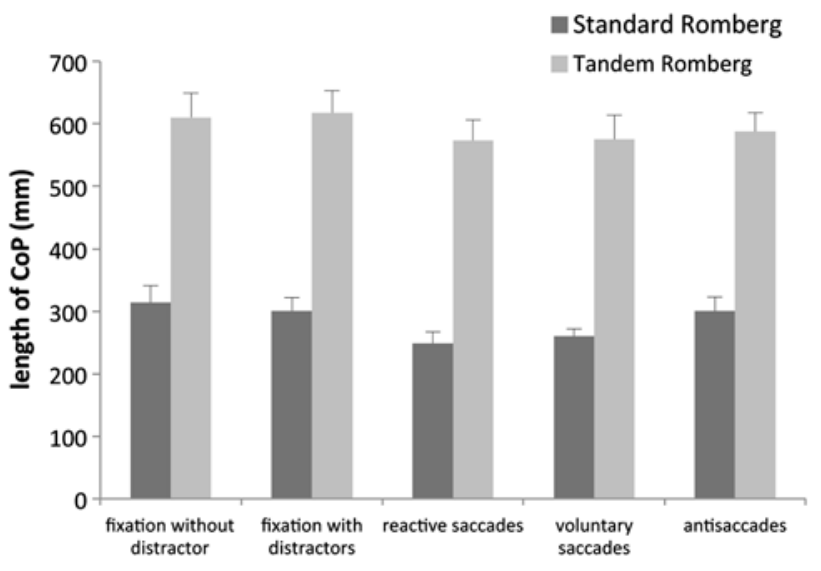

Fig. 4 Mean and standard deviation of length of CoP in SR and TR conditions in the five visual tasks (fixation without and with distractors, reactive and voluntary prosaccades, and antisaccades)

$\left(F_{(1,9)}=162.27, p<0.001\right)$. There was also a significant global effect of the visual task $\left(F_{(4,36)}=6.60, p<0.001\right)$, but this effect did not interact with the postural position $(F<1)$. Nevertheless, although the length of CoP was significantly greater in both fixation tasks (without and with distractors) than those measured in prosaccadic tasks (reactive as well as voluntary saccades) for both postural position, the length of $\mathrm{CoP}$ was significantly greater in the antisaccade task than in both prosaccade tasks $\left(F_{(1,9)}=7.26, p<0.05\right.$ and $F_{(1,9)}=7.25, p<0.02$, respectively, for reactive and voluntary prosaccades), only in the Standard Romberg position.

Analysis of the mean speed of CoP (Fig. 5) showed a significant effect of postural condition, with smaller values in the Standard than in the Tandem Romberg condition $\left(F_{(1,9)}=164.79, p<0.001\right)$. There was also a significant global effect of the visual task on the mean speed of $\operatorname{CoP}\left(F_{(4,36)}=6.43, p<0.001\right)$, but this effect did not interact with the postural position $(F<1)$. Nevertheless, similar to the length of CoP, values of the mean speed of $\mathrm{CoP}$ in both fixation tasks (without and with distractors) were significantly greater than those measured in prosaccadic tasks (reactive as well as voluntary prosaccades) for both postural conditions. While in the antisaccade task, the mean speed of CoP was significantly greater than the value reported in both prosaccade tasks $\left(F_{(1,9)}=7.26, p<0.05\right.$ and $F_{(1,9)}=7.25, p<0.02$ for the reactive and voluntary saccades, respectively) only in the Standard Romberg position.

\section{Discussion}

The goal of the study was to compare the effect of different visual tasks (fixation without and with distractors, 


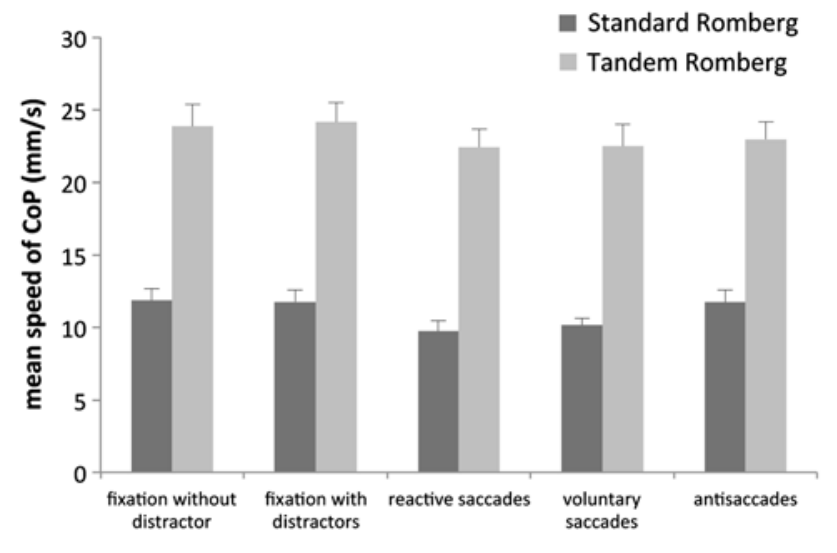

Fig. 5 Mean and standard deviation of mean speed of CoP in SR and TR conditions in the five visual tasks (fixation without and with distractors, reactive and voluntary prosaccades, and antisaccades)

prosaccades-reactive and voluntary-, antisaccades) on the surface, length, and mean speed of CoP when using two types of postural conditions (Standard Romberg and Tandem Romberg). Main findings are the important effect of postural positions, with more body sways in Tandem Romberg compare to Standard Romberg. A global effect of visual tasks showed less body sways when participant made saccades compared to fixation conditions. A difference between saccades was found in Standard Romberg position, in which antisaccades increased body sways compared to reactive saccades (for length and mean speed of $\mathrm{CoP})$.

Different effects of saccades and fixations on postural control

As suggested in the Introduction, the effect of visual tasks in postural control is still controversial. Our results showed that postural stability seems to be improved when the participant is making eye movements rather than staring at the fixation point. In saccadic tasks, the surface of CoP decreased with respect to the fixation tasks (fixation with or without distractors). These results are in line with those obtained by Uchida et al. (1979) and Rougier and Garin (2007) who reported an improvement of postural stability during the execution of saccades, and they contrast with the results showed by Glasauer et al. (2005) who found a decrease of postural stability during the execution of eye movements.

Further explanations on the decrease of body sways while performing eye movements are exposed below. Uchida et al. (1979) attributed this effect to signals related to the initiation or execution of saccades, which are integrated by the postural system via vestibulo-spinal and reticulo-spinal signals in the muscle tone of the lower limb. Furthermore, Rougier and Garin (2006) underlined the importance of attentional demands in postural control. Executing a secondary task (motor or cognitive) during a postural task allows attention not to be focused on postural control (Vuillerme and Nafati 2007), which leads to a better postural stability (automatic attentional system). Such improvement might be due to the fact that postural control becomes more automatic (Geurts et al. 1991; Melzer et al. 2001; Hunter and Hoffman 2001). Beilock et al. (2002) compared performance of novice and experienced golf putting groups during skill-focused and dual-tasks, and they showed that two groups increased performance in dual-task when the attention was not focused on sensorimotor skills. More generally, the focus of attention on body movements can be detrimental to the performance of well-learned skills (McNevin and Wulf 2000; Wulf and Prinz 2001).

Different effects of prosaccades and antisaccades on postural control

Our study shows that antisaccades, in contrast to prosaccades, lead to more body sway. Indeed, the length and mean speed of $\mathrm{CoP}$ increased during antisaccades in comparison with the prosaccade conditions, but just only in the Standard Romberg position. In the Tandem Romberg position, these differences between saccadic tasks are not present, perhaps in line with a ceiling effect in this more complex postural condition (Olivier et al. 2007). Surprisingly, this result had not been found either for the surface of CoP, perhaps because this parameter is not sensitive enough to be modified by the effect of different types of saccades. This result suggests the importance of measuring different spatial and temporal postural parameters for an accurate study of postural control (Winter 1995; Gagey and Weber 1999; Vuillerme et al. 2008). Recall that, the mean speed of COP has been shown to reflect neuromuscular energy used by the body for self stabilization (Maki et al. 1990; Geurts et al. 1993). Consequently, our results regarding the increase of the mean speed during the antisaccade task could reflect a difficulty to perform this task together with a postural test.

For a neuropsychological approach, cortical circuits implied in the triggering and executing of saccades in the antisaccade task are broader than those of prosaccades, because more cognitive processes are necessary to realize antisaccade task (Leigh and Zee 2006). Indeed, in order to correctly perform an antisaccade, the reactive saccade toward the peripheral stimulus has to be inhibited and a voluntary saccade in the opposite direction (antisaccade) has to be programmed. Neuropsychological studies have shown an important role of the frontal cortices when antisaccades are performed. For instance, Everling and Munoz (2000) revealed that several frontal structures (frontal eye 
field, dorsolateral prefrontal cortex, and supplementary eye field) are more activated during antisaccades than during prosaccades. Furthermore, Matsuda et al. (2004) reported increased activity in the inferior parietal cortex during antisaccades compared to prosaccades. Interestingly, Ettinger et al. (2008) showed that the antisaccade tasks activated an extensive fronto-parieto-subcortical network, and other studies found out that the parietal cortex (some regions in the intraparietal sulcus) is responsible for the vector inversion required to generate an antisaccade to the correct location (Clementz et al. 2007).

Different structures of central neural control are involved in the control of posture, namely the spinal cord and brainstem, basal ganglia, cerebellum, cerebral cortex: somatosensory, premotor, and motor cortices (Horak and Macpherson 1996). Some of these structures are implicated in postural regulation and in inhibition process, which may interfere with one another, leading to a decrease in postural performance during dual-task.

Finally, an interesting point of our study is the absence of significant differences between fixation and antisaccade tasks for the length and mean speed of CoP. This could suggest that the fixation task, frequently used in postural studies as baseline or control task, requires an increase in attentional resources allocated to control posture, which diminishes the stability of participants (Olivier et al. 2008). Moreover, the inhibition of saccades in the fixation with distractor condition is necessary to complete this fixation task successfully. This could explain similar results on postural parameters during fixation and antisaccade tasks.

\section{Effect of dual-tasks on postural control}

The dual-task paradigm is frequently used to assess attentional resources required to control our movements (Schaefer et al. 2010). Their resources vary with the complexity of the cognitive and/or sensorimotor tasks added to the motor task. It is now well established that even highly practiced activities, such as walking and postural control, are attention demanding (Huang and Mercer 2001). The first study of Kerr et al. (1985) described the attentional demand of postural control in young adults and suggested that cognitive tasks do not influence postural stability in the same way. So, the secondary task could either increase or decrease postural stability depending on the type of secondary task and on the attentional cost of such a task. Because the interference effects of our visual concurrent tasks on the posture performing are different, we can conclude that our results are in line with this proposition. An interesting model, called the U-shaped nonlinear interaction model, described by Lacour et al. (2008) explained why the effect of a secondary task during postural task varies. The U-shaped nonlinear interaction model suggests that the performance of an easy cognitive task can shift the focus of attention away from postural control and can lead to a better postural control relative to a single-task baseline. However, increasing the difficulty of the cognitive task can result in a degradation of postural sway. In accordance with this U-shaped model, Huxhold et al. (2006) showed an improvement of the postural sway under conditions in which participants were focusing their attention on an easy cognitive task (automatization of the postural control), as compared to focusing their attention exclusively on the execution of the sensorimotor task of balancing. When the attentional demand for the cognitive task increased (i.e., complex cognitive task), a degradation of the postural sway was observed. Our results are also in line with this U-shaped model. Indeed, an easy cognitive task (prosaccades) shifting the attentional focus away from postural control leads to a better automatic postural performance, while the increase in cognitive task complexity decreases postural performance (antisaccades). In a visual-postural dual-task when the visual condition is easy, the attentional resources are sufficient and the focusing on the realization of a reactive saccade, for example, automates the postural control, improving body stabilization. Moreover, when the complexity of the visual condition increases and more again when the complexity of the postural task increases also, the attentional resources are insufficient and the addition of an antisaccade task, for example, exceeds the attentional resources implying a decrease of postural stability because of too many attentional resources mobilized to control visual task. So, the visual and postural tasks study in our dual-task study seems to use the same attentional resources (i.e., unique attentional resources model (Wickens 1974). To summarize, the present study shows that an easily secondary task, as prosaccades, shifts the attentional focus away from postural control leading to a better automatic postural performance; in contrast, an increased complexity of the secondary task, as antisaccades, leads progressively to an overtaking of attentional capacities and a decrease in postural performance.

\section{Conclusion}

In conclusion, this study provides evidence about an effect on postural stability when performing saccadic eye movements. However, we showed the existence of interference between visual inhibition processes and postural executive ones at the level of the attentional resources which are pooled and shared between these two functional processes (oculomotor and postural control). Our results highlight that the complexity of the oculomotor task leads to a U-shaped postural performance. The secondary task depending on its attentional cost affects in a different way 
postural stability. Prosaccades direct participants' attention to postural control thereby improving postural stability; in contrast, a more complex task (i.e., antisaccades) could be responsible for shifting the attention away from postural control, decreasing postural performance.

Further studies, in which different types of eye movements and postural performance are simultaneously recorded, are needed to explore such an issue.

Acknowledgments Agathe Legrand was supported by the prize of "Association Posture et Equilibre," Grenoble 2010.

Conflict of interest Authors have no financial and personal relationships with other people or organizations that could inappropriately influence or bias their work in this study.

\section{References}

Barra J, Bray A, Sahni V, Golding JF, Gresty MA (2006) Increasing cognitive load with increasing balance challenge: recipe for catastrophe. Exp Brain Res 174(4):734-745

Beilock SL, Carr TH, MacMahon C, Starkes JL (2002) When paying attention becomes counter productive: impact of divided versus skill-focused attention on novice and experienced performance of sensorimotor skills. J Exp Psychol Appl 8:6-16

Belopolsky AV, Theeuwes J (2009) When are attention and saccade preparation dissociated? Psychol Sci 20(11):1340-1347

Blanchard Y, Carey S, Coffey J, Cohen A, Harris T, Michlik S, Pellecchia GL (2005) The influence of concurrent cognitive tasks on postural sway in children. Pediatr Phys Ther Fall 17(3): 189-193

Bove M, Fenoggio C, Tacchino A, Pelosin E, Schieppati M (2009) Interaction between vision and neck proprioception in the control of stance. Neuroscience 164:1601-1608

Chiari L, Rocchi L, Capello A (2009) Stabilometric parameters are affected by anthropometry and foot placement. Clin Biomech 17:666-677

Clementz BA, Brahmbhatt SB, McDowell JE, Brown R, Sweeney JA (2007) When does the brain inform the eyes whether and where to move? An EEG study in humans. Cereb Cortex 17(11): 2634-2643

Deubel H, Schneider W (1996) Saccade target selection and object recognition: evidence for a common attentional mechanism. Vision Res 36(12):1827-1837

Ettinger U, Ffytche DH, Kumari V, Kathmann N, Reuter B, Zelaya $F$ et al (2008) Decomposing the neural correlates of anti-saccade eye movements using event-related FMRI. Cereb Cortex 18(5): $1148-1159$

Everling S, Munoz DP (2000) Neuronal correlates for preparatory set associated with pro-saccades and anti-saccades in the primate frontal eye field. J Neurosci 20(1):387-400

Fischer B (1987) The preparation of visually guided saccades. Rev Physiol Biochem Pharmacol 106:1-35

Gagey PM, Weber B (1999) Posturology; Regulation and disruption of standing, 2nd edn. Masson, Paris

Geurts AC, Mulder TW, Nienhuis B, Rijken RA (1991) Dual-task assessment of reorganization of postural control in persons with lower limb amputation. Arch Phys Med Rehabil 72:1059-1064

Geurts AC, Nienhuis B, Mulder TW (1993) Intrasubject variability of selected force platform parameters in the quantification of postural control. Arch Phys Med Rehabil 74:1144-1150
Glasauer S, Schneider E, Jahn K, Strupp M, Brandt T (2005) How the eyes move the body. Neurology 65(8):1291-1293 (Epub $2005 \mathrm{Jul}$ 28)

Grasso R, Ivanenko Y, Lacquaniti F (1999) Time course of gaze influences on postural responses to neck proprioceptive and galvanic vestibular stimulation in humans. Neurosci Lett 273:121-124

Hallet P (1978) Primary and secondary saccades to goals defined by instructions. Vision Res 18:1279-1296

Horak FB, Macpherson JM (1996) Balance orientation and equilibrium. In: Shepard J, Rowell L (eds) Handbook of physiology. Exercise: Regulation and integration of multiple systems, section 12, ch. 7. Oxford University Press, NY, pp 255-292

Huang HJ, Mercer VS (2001) Dual-task methodology: applications in studies of cognitive and motor performance in adults and children. Pediatric Physical Therapy 13:133-140

Hunter MC, Hoffman MA (2001) Postural control: visual and cognitive manipulations. Gait Posture 13:41-48

Huxhold O, Li S-C, Schmiedek F, Lindenberger U (2006) Dualtasking postural control: aging and the effects of cognitive demand in conjunction with focus of attention. Brain Res Bull 69:294-305

Kerr B, Condon SM, McDonald LA (1985) Cognitive spatial processing and the regulation of posture. J Exp Psychol 11:617-622

Lacour M, Bernard-Demanze L, Dumitrescu M (2008) Posture control, aging, and attention resources: models and posture-analysis methods. Neurophysiol Clin 38:411-421

Lajoie Y, Teasdale N, Bard C, Fleury M (1993) Attentional demands for static and dynamic equilibrium. Exp Brain Res 97:139-144

Leigh RJ, Zee DS (2006) The neurology of eye movement, 4th edn. Oxford University Press, New York

Maki B, Holliday P, Fernie G (1990) Aging and postural control: a comparison of spontaneous- and induced-way balance tests. J Am Geriatr Soc 38:1-9

Matsuda T, Matsuura M, Ohkubo T, Ohkubo H, Matsushima E, Inoue $\mathrm{K}$ et al (2004) Functional MRI mapping of brain activation during visually guided saccades and anti-saccades: cortical and subcortical networks. Psychiatry Res 131(2):147-155

McNevin NH, Wulf G (2000) Carlson C effects of attentional focus, self-control, and dyad training on motor learning: implications for physical rehabilitation. Phys Therapy 80:373-385

Melzer I, Benjuya N, Kaplanski J (2001) Age-related changes of postural control: effect of cognitive tasks. Gerontology 47:189-194

Olivier I, Cuisinier C, Vaugoyeau M, Nougier V, Assaiante C (2007) Dual-task study of cognitive and postural interference in 7-yearolds and adults. NeuroReport 18(8):817-821

Olivier I, Palluel E, Nougier V (2008) Effects of attentional focus on postural sway in children and adults. Exp Brain Res 185: $341-345$

Palluel E, Nougier V, Olivier I (2010) Postural control and attentional demand during adolescence. Brain Res 1358:151-159 (Epub 2010 Aug 22)

Rougier P, Garin M (2006) Performing saccadic eye movements modifies postural control organization. Neurophysiol Clin 36(4):235-243

Rougier P, Garin M (2007) Performing saccadic eye movements or blinking improves postural control. Mot Control 11(3):213-223

Schaefer S, Lövdén M, Wieckhorst B, Lindenberger U (2010) Cognitive performance is improved while walking: differences in cognitive-sensorimotor couplings between children and young adults. Eur J Dev Psychol 7(3):371-389

Shumway-Cook A, Woollacott M (2000) Attentional demands and postural control: the effect of sensory context. J Gerontol A Biol Sci Med Sci 55(1):10-16

Stoffregen TA, Bardy BG, Bonnet CT, Hove P, Oullier O (2007) Postural sway and the frequency of horizontal eye movements. Mot Control 11(1):86-102 
Straube A, Paulus W, Quintern J, Brandt T (1989) Visual ataxia induced by eye movements: posturographic measurements in normal and patients with ocular motor disorders. Clin Vis Sci 4(2):107-113

Uchida T, Hashimoto M, Suzuki N, Takegami T, Iwase I (1979) Effects of periodic saccades on the body sway in human subjects. Neurosci Lett 13:253-258

Vuillerme N, Nafati G (2007) How attentional focus on body sway affects postural control during quiet standing? Psychol Res 71(2):192-200

Vuillerme N, Chenu O, Pinsault N, Fleury A, Demongeot J (2008) Can a plantar pressure-based tongue-placed electrotactile biofeedback improve postural control under altered vestibular and neck proprioceptive conditions? Neuroscience 155:291-296
White KD, Post RB, Leibowitz HW (1980) Saccadic eye movements and body sway. Science 208(4444):621-623

Wickens CD (1974) Temporal limits of human information processing: a developmental study. Psychol Bul 81:739-755

Winter DA (1995) Human balance and posture control during standing and walking. Gait Posture 3:193-214

Woollacott M, Shumway-Cook A (2002) Attention and the control of posture and gait: a review of an emerging area of research. Gait Posture 16(1):1-14

Wulf G, Prinz W (2001) Directing attention to movement effects enhances learning: a review. Psychon Bull Rev 8:648-660 